\title{
Lack of association between lipoprotein(a) genetic variants and subsequent cardiovascular events in Chinese Han patients with coronary artery disease after percutaneous coronary intervention
}

\author{
Zhi-Gen Li ${ }^{1,3}$, Guang Li $i^{1}$, Ying-Ling Zhou ${ }^{1 *}$, Zhu-Jun Chen ${ }^{1}$, Jun-Qing Yang ${ }^{1}$, Ying Zhang ${ }^{1}$, Shuo Sun ${ }^{1}$ \\ and Shi-Long Zhong ${ }^{2 *}$
}

\begin{abstract}
Background: Elevated lipoprotein(a) $[\mathrm{Lp}(\mathrm{a})]$ levels predict cardiovascular events incidence in patients with coronary artery disease (CAD). Genetic variants in the rs3798220, rs10455872 and rs6415084 single-nucleotide polymorphisms (SNPs) in the $L p(a)$ gene (LPA) correlate with elevated Lp(a) levels, but whether these SNPs have prognostic value for CAD patients is unknown. The present study evaluated the association of LPA SNPs with incidence of subsequent cardiovascular events in CAD patients after percutaneous coronary intervention ( $P C I)$.

Methods: TaqMan SNP genotyping assays were performed to detect the rs6415084, rs3798220 and rs 10455872 genotypes in 517 Chinese Han patients with CAD after PCI. We later assessed whether there was an association of these SNPs with incidence of major adverse cardiovascular events (MACE: cardiac death, nonfatal myocardial infarction, ischemic stroke and coronary revascularization). Serum lipid profiles were also determined using biochemical methods.

Results: Only the rs6415084 variant allele was associated with higher $L p(a)$ levels $[41.3(20.8,74.6)$ vs. $18.6(10.3$, 40.9) $\mathrm{mg} / \mathrm{dl}, \mathrm{p}<0.001]$. During a 2-year follow-up period, 102 patients suffered MACE, and Cox regression analysis demonstrated that elevated Lp(a) ( $\geq 30 \mathrm{mg} / \mathrm{dl}$ ) levels correlated with increased MACE (adjusted HR, 1.69; 95\% Cl 1.13-2.53), but there was no association between LPA genetic variants (rs6415084 and rs3798220) and MACE incidence $(p>0.05)$
\end{abstract}

Conclusions: Our data did not support a relationship between genetic LPA variants (rs6415084 and rs3798220) and subsequent cardiovascular events after $\mathrm{PCl}$ in Chinese Han CAD patients.

Keywords: Coronary artery disease, Lipoprotein(a), Major adverse cardiovascular events, Percutaneous coronary intervention, Single-nucleotide polymorphism

\footnotetext{
*Correspondence: gzghelain@163.com; zhongshilong@gmail.com

'Department of Cardiology, Guangdong Cardiovascular Institute, Guangdong

Academy of Medical Sciences, Guangdong General Hospital, 96 Dongchuan

Road, Guangzhou 510007, China

${ }^{2}$ Medical Research Center, Guangdong Cardiovascular Institute, Guangdong Academy of Medical Sciences, Guangdong General Hospital, 96 Dongchuan

Road, Guangzhou 510007, China

Full list of author information is available at the end of the article
} 


\section{Introduction}

Cardiovascular disease is the leading cause of morbidity and mortality worldwide. In past decades, multiple cardiovascular disease risk factors have been identified and used for risk stratification and outcome evaluations; lipoprotein (a) $(\mathrm{Lp}(\mathrm{a}))$ is one of the most attractive and promising risk factors.

$\mathrm{Lp}(\mathrm{a})$ is a plasma lipoprotein consisting of a cholesterolrich low density lipoprotein (LDL) particle with one apolipoprotein B100 (apoB100) molecule and an additional apolipoprotein(a) (apo(a)) protein attached via a disulfide bond [1]. Previous studies demonstrated that elevated Lp (a) levels are associated with increasing incidence and severity of cardiovascular diseases [2-7]. Furthermore, elevated baseline $\mathrm{Lp}(\mathrm{a})$ levels predict the subsequent cardiovascular event incidence in patients with coronary artery disease (CAD) after percutaneous coronary intervention (PCI) [8-10].

Serum Lp(a) levels are largely affected by Lp(a) gene $(L P A)$ variations, which varies widely across different races [11-13]. Recently, many single-nucleotide polymorphisms (SNPs) have been identified in LPA [11,12,14-16]. Among these polymorphisms, rs3798220 and rs10455872 are two common $L P A$ variants that have been studied intensively. Rs3798220 and rs10455872 are short variations in the $5^{\prime}$ haplotype block of $L P A$, which is located at the 6q27 chromosomal region. Both of these variations are strongly associated with serum Lp(a) levels in Caucasians, and each rs10455872 (G; 7.0\% frequency) and rs3798220 (C; $2.0 \%$ frequency) minor allele increased $\log \mathrm{Lp}(\mathrm{a})$ by 1.18 and 1.27 standard deviation units [17], respectively. A series of case-control studies demonstrated that rs10455872 and rs3798220 are significantly associated with CAD and myocardial infarction risk and are also associated with atherosclerotic burden, obstructed coronary artery number and an earlier CAD diagnosis [17-19]. However, whether these two LPA SNPs correlate to subsequent cardiovascular event risk for CAD patients after PCI is unknown. The present study was therefore aimed to explore the association between the two aforementioned SNPs in addition to another LPA SNP rs6415084, which is also a short variation in the 5' haplotype block of $L P A$ and correlates with $L p(a)$ levels [12], and the incidence of subsequent cardiovascular events in Chinese Han patients with CAD after PCI.

\section{Methods}

\section{Study population}

In total, five hundred and seventeen Chinese Han patients from Guangdong General Hospital were sequentially enrolled during May 2009 and August 2010. All of the patients were between 18 and 80 years old, unrelated Han Chinese male and female CAD patients. All of the patients received PCI before discharge. We excluded patients for any of the following: contraindication to aspirin or clopidogrel therapy, pre-existing bleeding disorders, pregnancy, lactating or planning to become pregnant, advanced cancer, hemodialysis and unsuccessful genotyping. This study has been registered in the Chinese Clinical Trial Registry (registration number: ChiCTROCH-11001198). All of the participants provided written informed consent for genetic analysis. The Guangdong general hospital ethics committee approved the study.

\section{Genotyping}

Genomic DNA was extracted from $4 \mathrm{ml}$ EDTAanticoagulated blood with the PureGene DNA isolation kit (Gentra Systems, Minnesota, USA) according to the manufacturer's recommendations. Rs6415084 rs3798220 and rs10455872 of LPA were determined for each patient using the TaqMan genotype discrimination assay (Applied Biosystems, California, USA) following the manufacturer's instructions.

\section{Lipid profile determination}

Serum lipid profiles including total cholesterol, triglycerides, LDL-cholesterol (LDL-C), high-density lipoprotein cholesterol (HDL-C), apolipoproteinA (apoA), apolipoprotein $B(a p o B)$ and $L p(a)$ were determined by biochemical methods on the second day of each patients' admission. Lp(a) was measured in serum samples using sandwich enzyme-linked immunosorbent assays (ELISA) [Lp(a) ELISA kit, Yaji Biosystems, Shanghai, China] and a SYNCHRON LX20 UniCel DxC800 analyzer (Beckman Coulter Inc., USA); less than $30 \mathrm{mg} / \mathrm{dl}$ was considered within the normal range.

\section{Data collection clinical follow-up}

Baseline risk factors, coronary angiographic findings and medication use were recorded for all of the enrolled patients. Follow-up information was collected based on inpatient and outpatient hospital visits as well as telephone contacts with the patients or their families $6,12,18$, 24 months after PCI. The clinical end point was the cumulative incidence of major adverse cardiovascular events (MACE) including cardiac death, nonfatal myocardial infarction (MI), ischemic stroke (CT or MR scan confirmed) and coronary revascularization. Coronary revascularization included PCI (including atherectomy, balloon angioplasty and stenting) or coronary artery bypass grafting in the follow-up period. For subjects with multiple events, only the first event was considered for analysis.

\section{Data analysis}

Categorical data are reported as frequencies, and differences between groups were compared with the $x^{2}$ test. Fisher exact tests were used when the expected cell frequencies were less than 5. Continuous data are reported 


\begin{tabular}{|c|c|c|c|c|c|}
\hline \multicolumn{2}{|l|}{ Subjects } & \multirow{2}{*}{$\begin{array}{c}\text { All } \\
\text { patients } \\
\mathrm{N}=517 \\
\mathrm{n}(\%)\end{array}$} & \multirow{2}{*}{$\begin{array}{c}\text { Patients } \\
\text { without } \\
\text { MACE, } n=415 \\
\text { n (\%) }\end{array}$} & \multirow{2}{*}{$\begin{array}{c}\text { Patients } \\
\text { with MACE, } \\
\text { n= } 102 \\
\text { n (\%) }\end{array}$} & \multirow[t]{2}{*}{$P$} \\
\hline SNP ID & & & & & \\
\hline \multirow[t]{7}{*}{ rs6415084 } & Genotype & & & & \\
\hline & $\mathrm{CC}$ & $406(78.5)$ & 367 (78.6) & $39(78.0)$ & 0.250 \\
\hline & $C T$ & $105(20.3)$ & $94(20.1)$ & $11(22.0)$ & \\
\hline & $\pi$ & $6(1.2)$ & $25(1.3)$ & $0(0.0)$ & \\
\hline & Allele & & & & \\
\hline & C & 917 (88.7) & $828(85.2)$ & $89(89.0)$ & 0.302 \\
\hline & $\mathrm{T}$ & $117(11.3)$ & $144(14.8)$ & $11(11.0)$ & \\
\hline \multirow[t]{6}{*}{ rs3798220 } & Genotype & & & & \\
\hline & $C C$ & 433 (83.8) & $393(84.2)$ & $40(68.1)$ & 0.449 \\
\hline & $C G$ & $84(16.2)$ & 74 (15.8) & $10(21.3)$ & \\
\hline & Allele & & & & \\
\hline & $C$ & $950(91.9)$ & 860 (91.1) & $74(84.1)$ & 0.870 \\
\hline & G & $84(8.1)$ & 74(8.9) & $14(15.9)$ & \\
\hline \multirow[t]{6}{*}{ rs10455872 } & Genotype & & & & \\
\hline & $\mathrm{AA}$ & 515 (99.6) & 465 (99.6) & $50(100.0)$ & 1.000 \\
\hline & $A G$ & $2(0.4)$ & $2(0.4)$ & $0(0.0)$ & \\
\hline & Allele & & & & \\
\hline & A & $\begin{array}{r}1032 \\
(99.8) \\
\end{array}$ & 932 (99.8) & $100(100.0)$ & 1.000 \\
\hline & G & $2(0.2)$ & $2(0.2)$ & $0(0.0)$ & \\
\hline
\end{tabular}

Abbreviations: CAD coronary artery disease, $L P A$ Lp(a) gene, MACE major adverse cardiovascular event, SNP single nucleotide polymorphism.

as the mean (standard deviation) or median (interquartile range, quartile1-quartile3) for continuous variables, and differences between groups were assessed using a $t$ test or Mann-Whitney U rank-sum test according to distribution status. All of the SNPs were assessed for deviations from Hardy-Weinberg disequilibrium with the use of a $\chi^{2}$ test. If the minor SNP genotype frequency was less than $5 \%$, the minor genotype was combined with the intermediate genotype.

Survival curves were generated using the Kaplan-Meier method and compared using the Log-rank test; univariate and multivariate Cox proportional hazard regression was used to find associations with baseline clinical characteristics and 2-year incidence of MACE. Variables with $\mathrm{p}$ values $<0.10$ were entered into the multivariable model, and variables with $\mathrm{p}$ values $<0.10$ remained in the model. Because the rs6415084 minor genotype (TT) frequency was less than 5\% and only two rs3798220 and rs10455872 genotypes were detected in our subjects, a dominant effect model of Cox regression analysis was used to calculate the hazard ratio (HR) of separate SNP to the incidence of MACE and corresponding 95\% confidence interval (CI). The wild-type genotype (W)/W was coded as 0 , and the $\mathrm{W} /$ variant $(\mathrm{V})$ and $\mathrm{V} / \mathrm{V}$ genotypes combined were coded as 1 . The significance level for all of the statistical tests was $\mathrm{P}<0.05$. Data analyses were performed using SPSS version 17.0 (Statistical Product and Service Solutions, Chicago, Illinois, USA).

\section{Results}

LPA SNP genotype and allele frequency distribution

The LPA SNP genotype and allele frequency distribution are demonstrated in Table 1. Of the three SNPs studied, both rs6415084 and rs3798220 were prevalent in our cohort except rs10455872, for which the variant allele was present in only two patients (G). The variant rs6415014 $(\mathrm{T}), \mathrm{rs} 3798220(\mathrm{C})$ and $\mathrm{rs} 10455872(\mathrm{G})$ allele frequencies were $0.113,0.081$ and 0.002 , respectively. There were no significant differences in genotype and allele frequencies between patients with or without MACE (all p > 0.05).

\section{The effect of LPA SNPs on serum Lp(a) levels in Chinese Han CAD patients}

Patients with the CT/TT genotype had a significantly higher Lp(a) levels compared with those that have the rs6415084 CC genotype $[41.3(20.8,74.6)$ vs. $18.6(10.3$, 40.9) $\mathrm{mg} / \mathrm{dl}, \mathrm{p}<0.001]$. However, there were no significant differences in $\mathrm{Lp}(\mathrm{a})$ levels between patients with CC and CG genotype of rs3798220 [23.2 $(11.3,51.9)$ vs. 18.6 $(9.9,46.0) \mathrm{mg} / \mathrm{dl}, \mathrm{p}=0.411]$ (Table 2).

\section{Baseline characteristics and their effect on MACE}

A total of 517 patients made up our study cohort. During a 2-year follow-up, 102 patients (19.7\%) suffered at least one incidence of MACE (12.0\% coronary revascularization, $3.9 \%$ cardiac death, $1.7 \%$ non-fatal myocardial infarction, $1.9 \%$ ischemic stroke). The baseline characteristics of patients with or without MACE are described in Table 3. Multivariable Cox regression analysis demonstrated that systolic blood pressure (adjusted HR, 1.02; 95\% CI: 1.01-1.03), LVEF (adjusted HR, 0.97;

Table 2 Serum Lp(a) levels in patients carrying different LPA SNP genotypes

\begin{tabular}{|c|c|c|c|c|c|c|}
\hline \multirow{2}{*}{$\begin{array}{l}\text { SNP } \\
\text { genotype }\end{array}$} & \multicolumn{2}{|c|}{ rs6415084 } & \multirow[t]{2}{*}{$p$} & \multicolumn{2}{|c|}{ rs3798220 } & \multirow[t]{2}{*}{$p$} \\
\hline & $\mathrm{CC}$ & $\mathrm{CT} / \mathrm{TT}$ & & $\mathrm{CC}$ & CG & \\
\hline \multirow[t]{2}{*}{$\mathrm{Lp}(\mathrm{a})(\mathrm{mg} / \mathrm{dl})$} & 18.6 & 41.3 & $<0.001$ & 23.2 & 18.6 & 0.411 \\
\hline & $(10.3,40.9)$ & $(20.8,74.6)$ & & $(11.3,51.9)$ & $(9.9,46.0)$ & \\
\hline
\end{tabular}

Abbreviations: LPA Lp(a) gene, SNP single nucleotide polymorphism. 
Table 3 Baseline characteristics in CAD patients with or without MACE

\begin{tabular}{|c|c|c|c|}
\hline \multirow[t]{2}{*}{ Characteristics } & \multicolumn{2}{|c|}{ MACE } & \multirow[t]{2}{*}{$\mathrm{p}$} \\
\hline & Present, $n=102$ & Absent, $n=415$ & \\
\hline Age (yrs) & $64.8 \pm 12.1$ & $63.1 \pm 11.2$ & 0.168 \\
\hline Male (\%) & 86.3 & 81.4 & 0.251 \\
\hline Smokers (\%) & 30.4 & 39.3 & 0.155 \\
\hline Hypertension (\%) & 66.7 .00 & 56.70 & 0.105 \\
\hline Diabetes mellitus (\%) & 30.4 & 21.9 & 0.071 \\
\hline History of AMI (\%) & 35.5 & 36.8 & 0.782 \\
\hline History of stroke & 4.9 & 4.6 & 0.798 \\
\hline Previous $\mathrm{PCl}$ & 22.5 & 15.7 & 0.097 \\
\hline $\mathrm{SBP}(\mathrm{mmHg})$ & $134.9 \pm 23.2$ & $129.7 \pm 20.4$ & 0.022 \\
\hline Body mass index $\left(\mathrm{kg} / \mathrm{m}^{2}\right)$ & $20.8 \pm 7.6$ & $21.4 \pm 8.2$ & 0.751 \\
\hline Total cholesterol (mmol/L) & $4.39 \pm 1.27$ & $4.44 \pm 1.22$ & 0.681 \\
\hline Triglycerides (mmol/L) & $1.17(0.87,1.69)$ & $1.30(0.98,1.81)$ & 0.306 \\
\hline LDL-C (mmol/L) & $2.71 \pm 1.04$ & $2.75 \pm 0.99$ & 0.729 \\
\hline $\mathrm{HDL}-\mathrm{C}(\mathrm{mmol} / \mathrm{L})$ & $1.08 \pm 0.29$ & $1.10 \pm 0.30$ & 0.627 \\
\hline$\underline{L}(\mathrm{a})(\mathrm{mg} / \mathrm{dl})$ & $36.3(12.8,56.4)$ & $22.4(10.5,45.7)$ & 0.012 \\
\hline hs-CRP (mg/l) & $3.34(1.48,6.80)$ & $3.33(1.35,10.80)$ & 0.200 \\
\hline eGFR $\left(\mathrm{ml} / \mathrm{min} / 1.73 \mathrm{~m}^{2}\right)$ & $92.9 \pm 34.1$ & $97.5 \pm 33.7$ & 0.228 \\
\hline $\mathrm{HbAc1}(\%)$ & $6.52 \pm 0.98$ & $6.41 \pm 1.21$ & 0.496 \\
\hline LVEF (\%) & $56.0 \pm 13.7$ & $59.8 \pm 10.9$ & 0.003 \\
\hline \multicolumn{4}{|l|}{ Coronary type } \\
\hline Stable angina & 33.3 & 22.9 & 0.029 \\
\hline Unstable angina & 28.4 & 39.5 & 0.038 \\
\hline $\mathrm{AMI}$ & 38.2 & 37.6 & 0.904 \\
\hline Number of lesion vessels & $2.34 \pm 0.76$ & $2.15 \pm 0.81$ & 0.034 \\
\hline Three-vessel disease & 52.0 & 41.9 & 0.067 \\
\hline Left main disease & 16.7 & 11.8 & 0.188 \\
\hline Statins & 100 & 98.1 & 0.366 \\
\hline$\beta$-blockers & 74.5 & 81.4 & 0.103 \\
\hline ACE inhibitors/ARB & 81.4 & 80.7 & 0.881 \\
\hline
\end{tabular}

Abbreviations: $C A D$ coronary artery disease, MACE major adverse cardiovascular event, $A M I$ acute myocardial infarction, SBP systolic blood pressure, $A C E$ angiotensin converting enzyme, $A R B$ angiotensin receptor blocker, LDL-c low density lipoprotein cholesterol, HDL-c high density lipoprotein cholesterol, LVEF left ventricular ejection fraction, $h s$-CRP high sensitive reactive protein, eGFR estimated glomerular filtration rate, $P C l$ percutaneous coronary intervention.

95\% CI: 0.96-0.99), use of $\beta$-blockers (adjusted HR, 0.62; 95\% CI: 0.39-0.97) and elevated Lp(a) levels ( $\geq 30 \mathrm{mg} / \mathrm{dl}$ ) (adjusted HR, 1.77; 95\% CI: 1.19-2.63) were independent MACE predictors (Table 4).

\section{The effects of LPA SNPs on MACE incidence}

Figure 1 presents the Kaplan-Meier survival curves for the separate SNPs according to their genotypes. There were no significant differences in time to MACE according to the genotypes of separate SNPs (all p > 0.05). Cox regression analysis demonstrated that there were no significant associations between the LPA genetic
Table 4 Univariate and multivariate analysis for 2-year MACE incidence

\begin{tabular}{lcc}
\hline Univariate analysis & HR $(\mathbf{9 5} \% \mathrm{Cl})$ & $\mathbf{P}$ \\
\hline Diabetes & $1.54(1.01-2.34)$ & 0.047 \\
\hline Previous PCl & $1.56(0.98-2.49)$ & 0.060 \\
\hline Number of vessels with lesions & $1.32(1,03-1.70)$ & 0.030 \\
\hline$\beta$-blocker use & $0.65(0.42-1.02)$ & 0.060 \\
\hline SBP & $1.01(1.01-1.02)$ & 0.026 \\
\hline Lp(a) $\geq 30 \mathrm{mg} / \mathrm{dL}^{*}$ & $1.54(1.05-2.27)$ & 0.029 \\
\hline LVEF & $0.98(0.96-0.99)$ & $<0.001$
\end{tabular}

Multivariate analysis

\begin{tabular}{llc}
\hline Diabetes & $1.50(0.98-2.30)$ & 0.061 \\
\hline Previous PCl & $1.51(0.95-2.41)$ & 0.085 \\
\hline$\beta$-blocker use & $0.62(0.39-0.97)$ & 0.035 \\
\hline SBP & $1.02(1.01-1.03)$ & $<0.001$ \\
\hline Lp(a) $\geq 30 \mathrm{mg} / \mathrm{dL}^{*}$ & $1.77(1.19-2.63)$ & 0.005 \\
\hline LVEF & $0.97(0.96-0.99)$ & $<0.001$
\end{tabular}

*Lp(a)<30 mg/dl was used for reference, Multivariate analysis was adjusted for diabetes, previous PCl, number of lesioned vessels, $\beta$-blocker use, SBP, LVEF and $L p(a) \geq 30 \mathrm{mg} / \mathrm{dL}$. Abbreviations: LVEF left ventricular ejection fraction, $M A C E$ major adverse cardiovascular event, SBP systolic blood pressure, $P C I$ percutaneous coronary intervention.

variants (rs6415084 and rs3798220) and time to MACE; the adjusted HR (95\% CI) for rs6415084 and rs3798220 were $0.91(0.55-1.50)$ and $1.51(0.92-2.45)$, respectively (Table 5).

\section{Discussion}

In our study, we genotyped three LPA SNPs and evaluated the association of these SNPs with Lp(a) levels in Chinese Han CAD patients. We found that only the rs6415084 variant correlated to Lp(a) levels; we further explored the association of the two SNPs that were most prevalent in our cohort (rs6415084 and rs3798220) and found no association between these SNPs and subsequent cardiovascular event incidence after PCI.

Serum $\mathrm{Lp}$ (a) levels are, to a large extent, genetically determined by $L P A$ variations in many populations $[11,12]$, and genetic $L P A$ variations have been linked directly with CVD risk [5,7]. Notably, certain genetic LPA variants, such as SNPs rs3798220 and rs10455872, are strongly associated with both increased $\mathrm{Lp}(\mathrm{a})$ levels and CAD risk in Caucasians [17]. However, because of race differences, the genotype frequencies may vary across different races [11,12,17]. As an example, the rs 10455872 variant is prevalent and significantly associated with elevated $\mathrm{Lp}$ (a) levels in Caucasians; however, the variant allele frequency ( $G$ allele) of this SNP is very low $(<1 \%)$ in Chinese people without CAD [12]. We also found a similar low frequency of this SNP variant allele in our study cohort with CAD. The rs3798220 minor allele ( $G$ allele) frequency in the Chinese is relatively higher than the Caucasians (8.1\% vs. $1.4 \%)$; however, this variation was not 

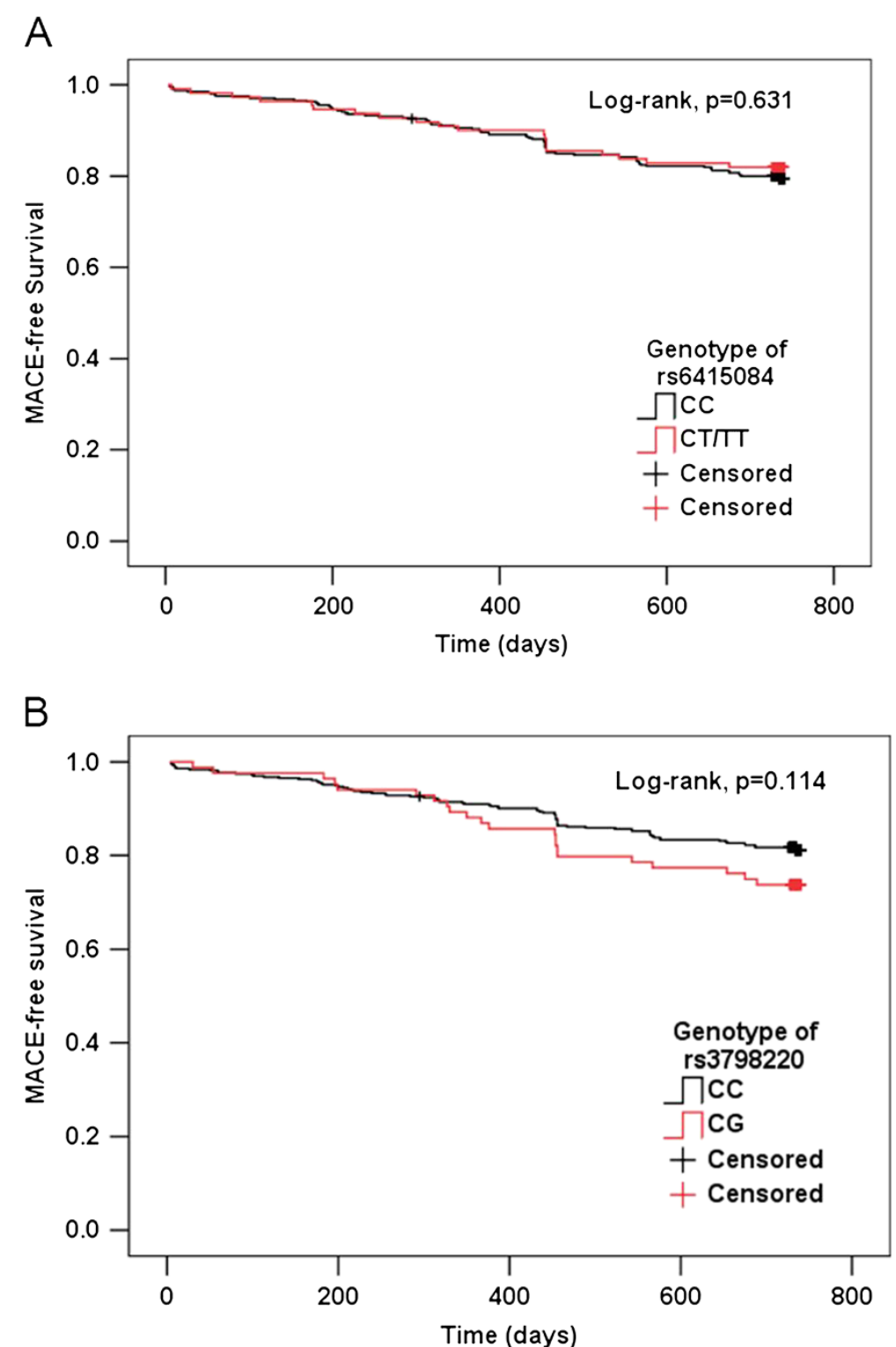

Figure 1 Kaplan-Meier survival curves of LPA SNPs and time to MACE. Panels A, B demonstrate the Kaplan-Meier MACE survival curves according to rs6415084 and rs3798220 genotypes, respectively. MACE: major adverse cardiovascular events, including cardiac death, nonfatal myocardial infarction, ischemic stroke and coronary revascularization.

Table 5 Association between Lp(a) genetic variants and 2-year MACE incidence

\begin{tabular}{lccccc}
\hline SNP ID & Genotype & Frequency & $\begin{array}{c}\text { MACE } \\
\mathbf{n},(\%)\end{array}$ & $\begin{array}{c}\text { HRadj } \\
\mathbf{( 9 5 \% ~ C l )}\end{array}$ & $\mathbf{p}$ \\
\hline rs6415084 & CC & $406(78.5)$ & $82(20.2)$ & 0.90 & 0.681 \\
& CT/ TT & $111(21.5)$ & $20(18.0)$ & $(0.55-1.48)$ & \\
rs3798220 & CC & $433(83.8)$ & $80(18.5)$ & 1.50 & 0.092 \\
& CG & $84(16.2)$ & $22(26.2)$ & $(0.94-2.41)$ & \\
\hline
\end{tabular}

HRadj: use a multivariate Cox regression model that has been adjusted for age, diabetes, hypertension, previous $\mathrm{PCl}$, 3-vessel disease, $\beta$-blocker use, total cholesterol, eGFR, LVEF and coronary artery disease type. associated with elevated $\mathrm{Lp}(\mathrm{a})$ levels in Chinese Han CAD patients. The reason for the lack of association is uncertain and may be partially explained by allele frequency differences or apo(a) size heterogeneity, which is the result of a genetically determined functional copy number variation within $L P A$ [20], but these hypotheses must be tested in further studies. In our study, rs6415084 was the only SNP that was associated with serum Lp(a) levels, which is consistent with a population-based study [12]. Interestingly, the rs6415084 variant allele frequency in our study was 0.11 , which was similar to that of Chinese people without CAD in a SHARE cohort [12,21]. These data suggest 
that this SNP may not play an important role in CAD pathogenesis, but this hypothesis must be assessed in further studies.

Accumulating evidence has suggested that $L p(a)$ plays an important role in promoting cardiovascular disease. Elevated Lp(a) levels ( $\geq 30 \mathrm{mg} / \mathrm{dl}$ ) reportedly predict subsequent cardiovascular event incidence in Caucasians with stable coronary disease, especially in patients with suboptimal LDL-C control ( $\geq 70 \mathrm{mg} / \mathrm{dl})$ [10]. Recently, Zhou et al. [9] determined that $\mathrm{Lp}(\mathrm{a})$ levels at admission are an independent risk factor for subsequent adverse cardiovascular events in Chinese patients with acute coronary syndrome, especially in patients younger than 60 years old. In our study, we found a similar association between elevated $\mathrm{Lp}(\mathrm{a})$ levels $(\geq 30 \mathrm{mg} / \mathrm{dl})$ and subsequent adverse cardiovascular events in $C A D$ patients after PCI; elevated Lp(a) levels were associated with 1.77-fold greater likelihood of MACE. Our data and others support the notion that $\mathrm{Lp}(\mathrm{a})$ may be used for risk stratification and outcome evaluations.

Although LPA SNP variants correlated with elevated Lp(a) levels [12,17], which were associated with high MACE incidence for CAD patients after PCI, there was no direct association between $L P A$ SNP variants and MACE incidence. $L P A$ variants rs3798220 and rs10455872 have been strongly associated with both increased $\mathrm{Lp}(\mathrm{a})$ levels and increased CAD risk [17]. However, because of racial differences, the rs3798220 and rs10455872 variant allele frequency in our cohort was different from the frequency in Caucasians. Both of these SNPs had no significant effect on serum Lp(a) levels in our cohort; therefore, one would not expect that they would have an effect on MACE incidence. Although the rs6415084 variant was strongly associated with higher $\mathrm{Lp}$ (a) levels, we did not discover a direct association between rs6415084 polymorphisms and MACE incidence during a 2-year follow-up. Our result is similar to a study by Nicholls et al., who determined that LPA SNPs rs2048327, rs3127599, rs7767084 and rs10755578 as well as haplotypes correlated to plasma $\mathrm{Lp}$ (a) levels, and $\mathrm{Lp}$ (a) levels $\geq 30 \mathrm{mg} / \mathrm{dl}$ were associated with MACE in stable CAD patients during a 3-year follow-up; however, this group did not observe any association of the LPA SNPs/haplotypes with increased prospective MACE risk.

CAD is a multi-factorial disease, and multiple genetic variations combined with environmental factors may result in phenotypic variability; therefore, factors that cause cardiovascular events in CAD are complicated. Compared to risk factors such as $\mathrm{Lp}(\mathrm{a})$ levels, disease severity, therapeutic reactions and therapeutic adherence are more effective measures for predicting CAD prognosis. In our study, elevated $\mathrm{Lp}(\mathrm{a})$ levels were an independent MACE predictor; however, elevated $\mathrm{Lp}$ (a) levels were a result of each $\mathrm{Lp}(\mathrm{a})$ genetic variant but not any specific SNP. Of the SNPs, rs3798220 explained approximately $8 \%$ of total (both genetic and individual-specific) variation in $\mathrm{Lp}(\mathrm{a})$ levels, and rs 10455872 explained approximately $25 \%$ of the variation. Together these two SNPs explained 36\% of the variation in $\mathrm{Lp}$ (a) levels in Caucasians [17]; however, in our study, rs6415084 explained only approximately $4 \%$ of total variation in $\mathrm{Lp}$ (a) levels (data not shown). Thus, it was not surprising that there was no significant association between the rs6415084 variant and MACE incidence. To date, our data and others do not support use of $\mathrm{Lp}(\mathrm{a})$ genetic variants for CAD risk stratification and outcome evaluations. However, because only three LPA SNPs were genotyped, and a relatively small patient sample size was involved in present study, further studies with more LPA SNPs and larger patient sample sizes will be required to confirm this conclusion.

\section{Conclusions}

Taken together with previous and present studies, our data did not support a relationship between genetic $L P A$ variants rs6415084, rs3798220 and subsequent cardiovascular event incidence after PCI in Chinese Han CAD patients; however, other studies will be required to confirm these findings.

\section{Competing interests}

The authors declared no conflict of interests.

\section{Authors' contributions}

The study was designed by $Y Z$ and $Z \mathrm{~L}$. All subjects data were obtained by ZL, GL, ZC, JY, YZ and SS. Experimental data was obtained by ZL and SZ. Data analyses were performed by ZL and SZ. The paper was written by $Z \mathrm{~L}$ and $\mathrm{SZ}$ and all authors read and approved the final manuscript.

\section{Acknowledgements}

This work was supported by the National Natural Science Foundation of China (81072701) and Science and Technology development projects of Guangdong province, China (2011b061200030). We also thank Dr Anping Cai, Dr Dehua Lai, and Dr Kequan Chen for their hard work to article polish.

\section{Author details}

'Department of Cardiology, Guangdong Cardiovascular Institute, Guangdong Academy of Medical Sciences, Guangdong General Hospital, 96 Dongchuan Road, Guangzhou 510007, China. ${ }^{2}$ Medical Research Center, Guangdong Cardiovascular Institute, Guangdong Academy of Medical Sciences, Guangdong General Hospital, 96 Dongchuan Road, Guangzhou 510007, China. ${ }^{3}$ Department of Geriatrics, Guangzhou First People's Hospital, Guangzhou Medical University, 1 Panfu Road, Guangzhou 510045, China.

Received: 15 August 2012 Accepted: 21 August 2013

Published: 27 August 2013

\section{References}

1. Gaubatz JW, Heideman C, Gotto AM Jr, Morrisett JD, Dahlen GH: Human plasma lipoprotein [a]. Structural properties. J Biol Chem 1983, 258(7):4582-4589.

2. Bostom AG, Cupples LA, Jenner JL, Ordovas JM, Seman L, Wilson PW, Schaefer EJ, Castelli WP: Elevated plasma lipoprotein(a) and coronary heart disease in men aged 55 years and younger. A prospective study. JAMA 1996, 276(7):544-548.

3. Berg K, Dahlen G, Christophersen B, Cook T, Kjekshus J, Pedersen T: Lp(a) lipoprotein level predicts survival and major coronary events in the Scandinavian Simvastatin Survival Study. Clin Genet 1997, 52(5):254-261. 
4. Danesh J, Collins R, Peto R: Lipoprotein(a) and coronary heart disease. Meta-analysis of prospective studies. Circulation 2000, 102(10):1082-1085

5. Kamstrup PR, Tybjaerg-Hansen A, Steffensen R, Nordestgaard BG: Genetically elevated lipoprotein(a) and increased risk of myocardial infarction. JAMA 2009, 301(22):2331-2339.

6. Virani SS, Brautbar A, Davis BC, Nambi V, Hoogeveen RC, Sharrett AR, Coresh J, Mosley TH, Morrisett JD, Catellier DJ, et al: Associations between lipoprotein(a) levels and cardiovascular outcomes in black and white subjects: the Atherosclerosis Risk in Communities (ARIC) Study. Circulation 2012, 125(2):241-249.

7. Erqou S, Kaptoge S, Perry PL, Di-Angelantonio E, Thompson A, White IR, Marcovina SM, Collins R, Thompson SG, Danesh J: Lipoprotein(a) concentration and the risk of coronary heart disease, stroke, and nonvascular mortality. JAMA 2009, 302(4):412-423.

8. Kardys I, Oemrawsingh RM, Kay IP, Jones GT, McCormick SP, Daemen J, VanGeuns RJ, Boersma E, Van-Domburg RT, Serruys PW: Lipoprotein(a), interleukin-10, C-reactive protein, and 8-year outcome after percutaneous coronary intervention. Clin Cardiol 2012, 35(8):482-489.

9. Zhou J, Cui X, Jin X, Fu M, Zhong C, Sun A, Hu K, Ge J: Association between Lipoprotein (a) level on admission and the incidence of subsequent cardiovascular events in patients with acute coronary syndrome. Int J Cardiol 2012, 158(3):464-466.

10. Nicholls SJ, Tang WH, Scoffone H, Brennan DM, Hartiala J, Allayee H, Hazen SL: Lipoprotein(a) levels and long-term cardiovascular risk in the contemporary era of statin therapy. J Lipid Res 2010, 51(10):3055-3061.

11. Chretien JP, Coresh J, Berthier-Schaad Y, Kao WH, Fink NE, Klag MJ, Marcovina SM, Giaculli F, Smith MW: Three single-nucleotide polymorphisms in LPA account for most of the increase in lipoprotein(a) level elevation in African Americans compared with European Americans. J Med Genet 2006, 43(12):917-923.

12. Lanktree MB, Anand SS, Yusuf S, Hegele RA: Comprehensive analysis of genomic variation in the LPA locus and its relationship to plasma lipoprotein(a) in South Asians, Chinese, and European Caucasians. Circ Cardiovasc Genet 2010, 3(1):39-46.

13. Deo RC, Wilson JG, Xing C, Lawson K, Kao WH, Reich D, Tandon A, Akylbekova E, Patterson N, Mosley TH Jr, et al: Single-nucleotide polymorphisms in LPA explain most of the ancestry-specific variation in Lp(a) levels in African Americans. PLoS One 2011, 6(1):e14581.

14. Luke MM, Kane JP, Liu DM, Rowland CM, Shiffman D, Cassano J, Catanese JJ, Pullinger CR, Leong DU, Arellano AR, et al: A polymorphism in the proteaselike domain of apolipoprotein(a) is associated with severe coronary artery disease. Arterioscler Thromb Vasc Bio/ 2007, 27(9):2030-2036

15. Ober C, Nord AS, Thompson EE, Pan L, Tan Z, Cusanovich D, Sun Y, Nicolae R, Edelstein C, Schneider DH, et al: Genome-wide association study of plasma lipoprotein(a) levels identifies multiple genes on chromosome 6q. J Lipid Res 2009, 50(5):798-806.

16. Ronald J, Rajagopalan R, Cerrato F, Nord AS, Hatsukami T, Kohler T, Marcovina S, Heagerty P, Jarvik GP: Genetic variation in LPAL2, LPA, and PLG predicts plasma lipoprotein(a) level and carotid artery disease risk. Stroke 2011, 42(1):2-9.

17. Clarke R, Peden JF, Hopewell JC, Kyriakou T, Goel A, Heath SC, Parish S, Barlera S, Franzosi MG, Rust S, et al: Genetic variants associated with Lp(a) lipoprotein level and coronary disease. N Engl J Med 2009, 361(26):2518-2528.

18. Koch W, Mueller JC, Schrempf M, Wolferstetter H, Kirchhofer J, Schomig A, Kastrati A: Two rare variants explain association with acute myocardial infarction in an extended genomic region including the apolipoprotein (A) gene. Ann Hum Genet 2013, 77(1):47-55.

19. Helgadottir A, Gretarsdottir S, Thorleifsson G, Holm H, Patel RS, Gudnason T, Jones GT, Van-Rij AM, Eapen DJ, Baas AF, et al: Apolipoprotein(a) genetic sequence variants associated with systemic atherosclerosis and coronary atherosclerotic burden but not with venous thromboembolism. J Am Coll Cardiol 2012, 60(8):722-729.
20. Kraft HG, Kochl S, Menzel HJ, Sandholzer C, Utermann G: The apolipoprotein (a) gene: a transcribed hypervariable locus controlling plasma lipoprotein (a) concentration. Hum Genet 1992, 90(3):220-230.

21. Anand SS, Yusuf S, Vuksan V, Devanesen S, Teo KK, Montague PA, Kelemen $L, Y i C$, Lonn E, Gerstein H, et al: Differences in risk factors, atherosclerosis, and cardiovascular disease between ethnic groups in Canada: the Study of Health Assessment and Risk in Ethnic groups (SHARE). Lancet 2000, 356(9226):279-284.

doi:10.1186/1476-511X-12-127

Cite this article as: Li et al.: Lack of association between lipoprotein(a) genetic variants and subsequent cardiovascular events in Chinese Han patients with coronary artery disease after percutaneous coronary intervention. Lipids in Health and Disease 2013 12:127.

\section{Submit your next manuscript to BioMed Central and take full advantage of:}

- Convenient online submission

- Thorough peer review

- No space constraints or color figure charges

- Immediate publication on acceptance

- Inclusion in PubMed, CAS, Scopus and Google Scholar

- Research which is freely available for redistribution

Submit your manuscript at www.biomedcentral.com/submit
C) Biomed Central 